\title{
Knowledge exchange with Sistema Scotland
}

\section{Introduction}

Knowledge transfer and knowledge exchange within higher education have become increasingly important as governments seek to maximise the benefits produced by university researchers and ensure that these are made available to the business, industry, service and public sectors. It is seen as vital for efficient and effective working and as a civic responsibility: 'if we fail to restructure the way we create use and communicate knowledge we commit an injustice to the populations we serve' (www.theknowledgexchange.co.uk). For the UK Economic and Social Research Council, knowledge exchange is 'about starting a conversation' and has, as its essence, dialogue and reciprocity (www.esrc.ac.uk/ESRCInfoCentre/Support/knowledge_transfer/index.aspx). This paper reports on a knowledge exchange project, funded by the Scottish Funding Council and with the aim of improving the 'two-way flow of people and ideas between the research environment and wider economy, thereby contributing to national prosperity, the quality of life of citizens, and cultural enrichment of our society' (Scottish Funding Council, n.d). The project was undertaken by a group of researchers from three higher education institutions with a combined knowledge of education, music and psychology which has guided their knowledge exchange activities with the project partner and among themselves. The project partner was Sistema Scotland, a charity which is attempting to implement a major programme of social change, originating in Venezuela, within a disadvantaged area of Scotland, and therefore a highly appropriate focus for knowledge exchange. The paper outlines the development of Sistema Scotland and the programme, El Sistema, on which it is 
based. It details the knowledge exchange activities undertaken, which used Derrida's (1993) notion of aporia to try to engage Sistema Scotland with different perspectives and understandings, and a practical method for conducting meetings based on Open Space Technology. The various 'encounters’ with children, service providers and stakeholders are reported and this is followed by a critique of the processes of knowledge exchange which were both permitted and prohibited. The paper ends with a discussion of the conditions that are necessary for knowledge exchange to be successful.

\section{Sistema Scotland: From Caracas to the Raploch}

El Sistema (which translates as 'The System') has achieved a very high profile because of its innovative aims of achieving social equality for young Venezeulans from disadvantaged backgrounds through the agency of orchestral training and has been successfully implemented across the country for the past 30 years, with 180 orchestral centres serving 350,000 children in Venezuela. El Sistema was founded in 1975 under the directorship of maestro Jose Antonio Abreu and has produced scores of world-class players, including the recently appointed Music Director of the Los Angeles Philharmonic, Gustavo Dudamel, aged 28. Maestro Abreu's vision is spiritual, seeing music as having the potential to touch humans and 'to generate values that profoundly transform the spirit of the child who values the orchestra' (Maestro Abreu, http://www.fanfaire.com/Dudamel/abreu.html). He also sees being in an orchestra as an act of community and belonging. The El Sistema approach is highly structured and disciplined, combining methods derived from the Suzuki and Kodály systems of music education with a great deal of singing, and with an emphasis on playing together. It also integrates Venezuelan folk music and the work of Latin 
American composers, exposing children to masterpieces early on and allowing them to grow and progress within these (Booth 2009; Chang 2007).

This combination of high musical excellence, entirely driven by an ethos of social equality and participation in a context that includes significant deprivation, has generated considerable excitement and Lieberman (2009) suggests it is starting to inspire a global movement of using orchestral music to break the cycle of poverty; the conductor Sir Simon Rattle has proclaimed, 'there is no more important work that is being done in music now than is being done in Venezuela.' (www.fanfaire.com/Dudamel/advocates.html). The Simon Bolivar orchestra (a product of El Sistema) attracted a great deal of press attention and interest from across the education and social inclusion communities in the UK in the summer of 2007, at the London Proms and the Edinburgh Festival and during their 2009 visit to London, for the very high musical quality, energy and vitality of its performances.

El Sistema excited the imagination of the Chair of the Joint Board of the Scottish Arts Council and Scottish Screen, Richard Holloway, who dreamed of bringing the project to one of Scotland's most deprived areas, the Raploch Estate in Stirling. He saw the Raploch Estate as an ideal place to start because of its location in the centre of Scotland and its position at the top of the regional deprivation index, with high unemployment rates, poor health, poor quality housing, low educational achievement and a lack of opportunity (www.raploch.com/RaplochToday.aspx). Holloway envisaged the potential for the method to produce high class players and also to transform the community and mobilised support from some key organisations, including the BBC Scotland, the BBC Scottish Symphony Orchestra, Drake Music 
(an organisation which facilitates the participation of disabled people in music) and Stirling Council, the local authority, and established the first European 'outreach' location of El Sistema. A company, given the name Sistema Scotland, was set up under the directorship of Dr Holloway, with the appointment of Nicola Killean as Project Director, and was formally launched in 2008 amid considerable publicity. The orchestral programme delivered by Sistema Scotland was given the name Big Noise. Sistema Scotland has a formal partnership agreement with The State Foundation for the National System of Youth and Children's Orchestras of Venezuela (FESNOJIV), led by Maestro Abreu. Seven classically trained musicians (all strings players) were appointed to work with the children. They began in 2008 with a summer school in Castleview, a new ‘Community Campus’ established through a substantial urban regeneration scheme and which located two primary schools (one catholic and one non-denominational) and a special school on the same site, together with community, further education and leisure services. Since the start of the 2008/2009 school year, children aged five have received three hours of lessons per week during school time. An intensive after-school programme is offered throughout the year for children aged six to eight.

\section{Knowing me, knowing you: the knowledge in knowledge exchange}

Our aim was to explore the interactions between us as researchers, the project itself and policy and to improve the flow of knowledge exchange between each of these elements. We also wanted to investigate how we worked together as a multidisciplinary team. Researchers from the three partner institutions in this project all had experience of working on public policy in their specialist fields of education, 
social inclusion, the arts and culture as a means of social regeneration, and music education policy. The research team had distinct but complementary research interests, summarised as focussing on the social, particularly social inclusion and the arts (Institution), the personal and psychological (Institution) with particular research expertise in community music and music psychology, and the musical, policy consultancy and grass roots knowledge from (Institution). The research group named itself the Sistema Scotland Knowledge Exchange Team (SSKET).

Multidisciplinary research has been much encouraged by Research Councils and viewed positively as contributing to knowledge by adopting 'a single set of imperatives and approaches by fusing established research disciplines together’ (http://www.esrcsocietytoday.ac.uk/esrcinfocentre/opportunities/CCFA/) . One of our aims was to maximise effective multidisciplinary working and to engage in knowledge exchange activity, not just with external partners but among ourselves too. We recognised that, as a team, we brought different theoretical perspectives, experiences, backgrounds and methods, as well as prejudices, biases and tolerances. This array of knowledge brought to the project by the researchers and the Sistema Scotland project officers was shared and transformed by the exchange process. However, 'knowledge' in usage is not pure and abstract: it is couched in the professional perspectives of the participants, and so the process of exchange may be better understood in the context of innumerable implicit professional beliefs and motivations. These surfaced in the regular team meetings and often prompted fascinating and creative exchanges. We took the decision to be more explicit about this, and to acknowledge and articulate our fields of knowledge through the 
production of a series of statements, which we undertook in different ways. These are summarised below.

(Author's) expertise includes the study of music as human communicative practice, through the combination of two strands of work - engagement with community music practice and education in Scotland, and research into embodied music cognition (Author 2007; 2009). In relation to this project, Author's position was informed by the work of music educationalists and academics which has demonstrated the social value of group music-making, as well as the developmental benefits that may arise with practical music education (McPherson 2006; Pitts 2005; Schellenberg 2005).

Many of Research Officer (Author's) interests in community music and community development overlap with (Author's) but with (Author) approaching these from a background as a professional musician and teacher. Her knowledge includes learning by ear, understanding idiom, making wider connections to cultural context, traditional music in a community setting, event organizing, how both adults and children learn, and Freire's thinking on education and adult learning. (Author) interests also involve health promotion and the connections between music and health.

(Author) extended her statement beyond areas of knowledge into personal interests and commitments. These include teacher education, philosophy, sociology, and a commitment to social justice, inclusion and children’s rights. Her knowledge encompasses education as a field of study, inclusion (policy, legislation and practice), socially engaged arts practices, children's rights, theoretical perspectives, particularly the philosophers of difference (Derrida, Foucault and Deleuze and Guattari; Author, 
2008), theories of social capital (of Bourdieu, Putnam and Coleman; Author et al 2009) and their applications in education, research methodology and methods, particularly participatory methodologies, qualitative research methods and research ethics.

(Author) stated that she "knew about" music and performing arts education policy and strategy in Scotland, the landscape of provision in UK, instrumental tuition and workforce issues, conservatoire/elite provision and learning, institutional roles, the fit between them and the politics of all the above. Among the topics she could 'wing it on’ were music and performing arts education in schools, methods of learning and teaching in music, Scottish traditional music and social inclusion in the arts (Author 2009). She confessed to being 'out of it' on the theoretical literature on any of the above.

This simple exercise proved very fruitful. We were able to identify and acknowledge common interests and knowledge domains (e.g. Author and Author) both being involved with the search for effective methods of evaluating community music projects and bringing both practical experience and theoretical research to bear on this; and in various “insider” musicians’ perspectives) as well as “solos” (e.g. Author's particular interest in putting the philosophers to work on educational problems such as inclusion and Author’s more arts-policy, “applied” perspective).

These particular professional and research interests naturally informed the starting point of exchanges with Sistema Scotland. The longevity of El Sistema, its inclusive approach, and the sheer vitality of its musical output make for a fascinating topic, and 
so the opportunity to observe the effects of a similar music programme with such vivid and far-reaching aims as Big Noise was irresistible; like many other professionals working within the Scottish music and education worlds, we were drawn to the project.

An important element which cemented our good team working was our honesty: one author admitted to being tantalized by the idea of musical apprenticeship but not being ready to take it forward; another admitted to 'winging it' on anything theoretical. Our acknowledgment of our identities as researchers or musicians (and often both), our shortcomings as well as areas of strength has produced many moments of what we consider to be authentic knowledge exchange and is testament to the confidence and productiveness of our work together.

\section{Doing knowledge exchange - uncertainly}

The philosopher Derrida (1993) has suggested that one is often faced with competing obligations and these may present people with considerable uncertainty and even an incapacity to act. His own personal example, as an Algerian living in France, concerned ethnicity and identity and was the obligation of, on the one hand, how a nation might respond to differences and minorities and, on the other hand, the 'universality of formal law, the desire for translation, agreement and univocity, the law of the majority' (Derrida 1992, 78). Derrida named these moments of 'not knowing where to go' $(1993,12)$ aporias and suggested that far from being troublesome, these could be highly productive moments where justice is possible because of the very uncertainty that is generated. Derrida argued that the moment 
where decisions are made is when closure is created and injustice is produced because one of the two possibilities is excluded:

\footnotetext{
When the path is clear and given, when a certain knowledge opens up the way in advance, the decision is already made, it might as well be said that there is none to make; irresponsibly, and in good conscience, one simply applies or implements a program ... It makes of action the applied consequence, the simple application of a knowledge or know how. It makes of ethics and politics a technology. No longer of the order of practical reason or decision, it begins to be irresponsible (Derrida 1992, 41-45, original emphasis).
}

The aporia, in contrast, allows the two possibilities to be held open, without privileging one over the other and is thus more responsible. The aporia, because it involves an explicit engagement with the other and an engagement with undecidability, has been recognised as having potential value in educational policy and practice as well as in wider civic engagement (Author 2008; Critchley 1999; Egéa-Kuene 2001).

The knowledge exchange team has sought to place aporias at the heart of the process of knowledge exchange and to present these to the Sistema Scotland project officers, not as sets of alternatives but as at least two equally important obligations and to question them on potential areas of privileging. This differs from recommended 'good practice' in knowledge exchange which removes the reciprocity from the exchange process, emphasising instead a more singular form of transfer, and encourages a reduction of complexity and simplifying of the message to be passed on. Abernathy et al (2001), for example, advocate the adherence of the knowledge exchange message to the 'Five Cs' - clear, concise, consistent, compelling and continuous' in order to 
make an impact. Meanwhile the Higher Education Funding Council and Department of Trade and Industry invite successful academics to submit 'recipes' for knowledge exchange (www.kegoodpractice.org/about/about/php), while in Scotland, Step Change 2009 promises a ‘distinctively Scottish approach’ to knowledge exchange (http://www.napier.ac.uk/randkt/kestepchangeDevelopment/Pages/home.aspx). There is little evidence of whether such reductionist approaches, which have their roots in commercialisation and technology transfer activities of the late 80s and 90s (Ozga \& Jones 2006; Lingard \& Ozga 2007) and which form part of a complex 'governance turn’ (Ball 2009, 537; Ozga 2009), have any success - but it is difficult to see what can be gained from removing complexity from the knowledge exchange process, especially where it involves organizations concerned with public service.

The concentration on knowledge exchange in this project has itself been an aporia: the Sistema Scotland project officers impressed upon the researchers the need for clarity about the vision, and a certain urgency about getting started and obtaining evidence of impact. Whilst sympathetic to these needs, we have had concerns about how such a move towards clarity, and an imperative to 'act now' could, following Derrida (1992), produce injustice because it closes down possibilities. We have tried to alert them to these dangers and to the impossibility of producing evidence, certainly in the short term, of the achievement of some of their extremely ambitious objectives, particularly regarding their claim about the positive impact of Big Noise on the community, and the security of their future funding.

\section{Knowledge exchange 'encounters' through Learning Spaces}


A key part of the SSKET pilot project involved engaging with the public. We wanted to create a space for discussion about the meaning of music and music-making in children's lives, and the ways in which they might connect with Big Noise . In order to achieve this, a series of four Learning Space meetings were organised. The aims underpinning these meetings were to:

- Pilot creative methods of communication using Open Space Technology (www.openspaceworld.org)

- Bring together diverse groups and individuals connected to or with an interest in Big Noise

- Encourage flow of ideas, dialogue and connectivity across sectors and stakeholders.

- Identify themes and issues regarding the development of the project

- Work together in an open way and listen to everyone’s ideas.

Meetings were structured as a series of Learning Spaces, based on Open Space Technology and adapted for our policy partners and ourselves. The Open Space approach, established by the businessman Harrison Owen, has been described as 'passion with responsibility’ and as ‘chaos and creativity’ (www.openspaceworld.com); it is simultaneously loose, because the agenda is not set, and highly structured, using the responses of the participants to a single open question in order to determine activities and outcomes. While each meeting differed to suit the groups involved, participants in each of the Learning Spaces were asked to reflect on the common title - 'You, me, and Big Noise - Playing Our Part'. The ethos of the meetings was inclusive: participants identified issues and set their own agenda. This meant that topics for discussions were entirely relevant to those in the room, and not imposed from outside. Participants were viewed as the experts, bringing their knowledge and ideas to the gathering. 
Each of the four Learning Spaces included a hands-on creative element (poster making; a twenty minute violin lesson; a bagpipe lesson; and finally, a ceilidh). The aims of the Learning Spaces were to have fun and to create a learning experience by confronting participants with something new. They also had the more serious aims of dissolving some of the existing hierarchies and power imbalances by emphasising the importance, and necessity, of everyone having a say and this distinguishes them from the kind of 'expansive learning' offered by Engestrom (1987). Learning Spaces were an explicit attempt to operationalise aporias by providing, literally, an open space in which people were exposed to at least one other point of view. It was hoped that this would stimulate learning among both the participants in meetings and the Sistema Scotland project officers, when the perspectives were reported back to them.

After discussion with Sistema Scotland about who to involve in the Learning Spaces, it was decided to target the following groups:

1. School children -involved and not involved in Big Noise

2. Service Providers - Stirling Council Community Services, Children’s Services, and local voluntary organisations and groups.

3. Sistema Scotland stakeholders - the board of directors, funders and advisors to the project.

4. The Raploch local community including parents, friends and families.

\section{Learning Space One - School children}

While the Open Space method is gaining popularity in workplace environments and in consultations with young people, it does not appear to have been tried with seven to 
eight year-olds. The first Learning Space was held during school time with 40 children from the two mainstream schools and three children from the special school on the Campus, SSKET recorded conversations and narratives of their thoughts, feelings, and ideas about their lives, Big Noise, the Raploch, and music-making.

Through use of photo elicitation and poster-making five discussion themes were generated by the children:

- Friends and family

- The Big Noise musicians

- A special day

- Music on the telly

- Instruments I like

The main findings from this day were that Big Noise is a significant part of the children's daily lives in the Raploch, whether they are directly involved or not. The Big Noise musicians (tutors) have become important role models in the school community, with male role models especially significant in the predominantly female environment of the primary school. Big Noise community events, such as a project launch, a Christmas party, end of term concerts, and a musical outreach play-bus, hold great significance for the children. These events, along with the very successful 'Take a Musician Home for Tea' initiative, were important opportunities for families to be involved and this was reported as meaningful to the children. An awareness of classical music and classical instruments is becoming a part of the children's lives 
alongside that of the dominant pop and TV culture - although the two worlds remain compartmentalised in the children's minds.

\section{Learning Space Two - Service Providers - Stirling Council Community Services,}

\section{Children's Services, and local voluntary organisations and groups}

Around 15 people attended this Learning Space. Although numbers were low, there was an even representation of the groups invited to attend. This meeting focussed on written and verbal communication, using traditional Open Space methods: post-its, flipcharts, and graffiti walls to share ideas and to generate issues for further discussion.

The key elements to emerge included an overwhelming support for Big Noise and recognition of its importance in the lives of the children involved. These were balanced with concerns about the sustainability of funding and the future development of Big Noise in the Raploch and elsewhere. A wide range of ideas was raised, including developing and extending structures for communication with, and involvement of, Raploch community and service providers; the choice of musical genre and its transferable benefits; and how children will be integrated into secondary school music activities.

It is interesting to note that these questions also dominated at subsequent Learning Spaces. Being only in its first year of existence and at an experimental stage in the Scottish context, there are many unknowns surrounding Sistema Scotland. The aim of dissolving hierarchies and encouraging wide-ranging discussion was partially achieved but would have worked better with greater numbers, and would have allowed critical voices to be heard but not exposed. However, as one participant reported: 
Yesterday was an important event; the first that I've attended where there has

been a wider ranging discussion about the system [Sistema] in the Stirling context.

\section{Learning Space Three: Sistema Scotland stakeholders - The Board Members, funders and advisors to the project}

This Learning Space was the most challenging of the four, taking place following protracted discussions with Sistema Scotland around what constituted a 'stakeholder'. Sistema Scotland was keen to use the opportunity to bring together only its immediate stakeholders, in order that they could focus specifically on how to support the project. The researchers, not sharing this objective, preferred a wider definition of stakeholder which would include anyone who saw themselves as having a stake in the project, such as those in the wider music education field. This discussion highlighted the sometimes differing priorities of researchers and Sistema Scotland, the policy partners. Sistema Scotland's priority was to hone its support network and focus on its financial survival, while our remit, from the Scottish Funding Council, was to dig deeper and to explore the complexities and processes of knowledge exchange, with less of a focus on outcomes.

For the sake of diplomacy, and to build trust between us, SSKET agreed to work with the more limited version but with continued reservations about whether the meeting would work with little diversity and with limited numbers of participants. In the event, numbers were disappointing, with 16 attending and 19 sending their apologies. Interestingly, participants themselves commented on the limited scope of the meeting, and some were also critical of the Open Space method which, as we anticipated, was not effective in this instance. However, a range of issues was identified by all of the 
participants, many of which resonated with questions raised in the previous Learning Space.

Themes common to the previous Learning Space included uncertainty over future funding of Sistema Scotland and how to justify it; what happens when Rapoloch children are of secondary school age; how to connect with school and youth orchestras; and issues around wider community involvement and the long term impact on the Raploch. An issue that uniquely featured in this Learning Space was frustration about the need for research and questions concerning how to measure the success of the project in the context of the strongly-held belief amongst stakeholders that Sistema simply 'works'. While this Learning Space produced useful information in piloting methods, the researchers felt their lack of autonomy in the process had negatively impacted on its success, resulting in a lack of diversity amongst participants, an unwillingness to engage with the Open Space method, and a less fruitful experience for those taking part.

\section{Learning Space Four: The Raploch local community - parents, friends and families}

In many ways this was the most eagerly anticipated of all the meetings, as it was completely open to the public. It also presented the greatest uncertainties in terms of attendance and engagement. With the help of Raploch Community Partnerships, 1250 households were invited to come and talk to us with the offer of free childcare, food, and a ceilidh to end the day. The aim was to make the event as accessible and welcoming as possible, with less emphasis on the written word and more on hearing people’s stories. 
Learning Space Four was therefore set up as a marketplace bazaar, filled with artefacts and images to stimulate discussion and ideas. Slide shows, a BBC film about the Raploch, photographs of Big Noise and other images around music, instruments, and cardboard replicas used as learning tools by Big Noise were on display. The SSKET team recorded what participants had to say, and themes were identified and discussed in small, informal groups.

While the number of participants was again low, but similar to numbers attending previous meetings, this meeting was felt to be one of the most successful: rich data were collected, and the innovative and creative format worked well. Familiar themes emerged through the discussions, including enormous support and respect for Big Noise; concerns about how the programme will develop and about distribution of resources; and debate around similarities and differences between Scotland and Venezuela. The unique aspects identified at this meeting concerned the positive opportunities for Big Noise children and the impact it has had on the wider family. Discussion also focussed on the changing community as the Raploch undergoes massive regeneration.

\section{Aporias and openings}

We noticed that in overcoming the huge hurdles associated with the launch of such an ambitious charity - primarily, funding and the support of governmental institutions the individuals driving Sistema Scotland have adopted a professional perspective that prioritises a need for unquestioning faith in the intrinsic value and efficacy of the programme. This bold position provides a tremendous energy to the operation of Sistema Scotland, but - like any agenda-driven professional perspective - it is not 
without limitations. These could be seen to include a narrow and focused vision of the programme's place within an existing community and services infrastructure, for example, and a 'missionary' stance in relation to the Raploch community, reliant on statements of faith in the process from all involved.

These examples of the context in which Sistema Scotland's own knowledge is made manifest contrast with the professional perspectives of the researchers. Despite a mutual interest in the topic of accessible music education and a shared belief in the social benefits of community music projects, the researchers' own context of knowledge was characterised by a more circumspect approach to large-scale social intervention. These contrasting contexts of knowledge (reflective versus audacious planning; top-down versus bottom-up decision-making) lay beneath many of the aporias.

A significant number of competing obligations surfaced. We chose to read these, in Derrida's (1993) terms, not as oppositions, but as aporias, even though these produced some quite profound tensions between the researchers and the policy partners, Sistema Scotland. Most of these aporias concerned Sistema Scotland and their aspirations:

- Portraying the Raploch as 'in need' of high level social worker involvement, in order to secure funding; but recognising the damaging nature of such portrayal and the negative reaction from the community. 
- Wanting to 'make a Big Noise' in terms of PR and media; and simultaneously recognising the importance the low-key organic, solid development of the project that is required in order to build sustainability.

- Succeeding in generating a huge media and public interest; and then living with the consequences of that interest - in the stereotypes of disadvantage, and in the significant pressure to produce results.

- Wanting the community 'on board'; but also wanting to keep parents at arms length, with controlled access to information and publicity, until the programme is established.

- Concerned at once with both social change; and the aspiration to grow a strong, musically excellent orchestra.

- Insistence on the orchestral form being a superior method for creating social transformation; and also recognizing that this has been achieved in other musical settings.

- Proud claims of operating the purest form of the Venezuelan system; but also speaking of adapting and changing as the situation demands.

- Giving public assurances of the sustainability of Big Noise and the investment in the children’s future; yet needing to secure significant funding for that future beyond 2011.

- Recognising that Big Noise is a long term programme of change; and also seeking short-term evidence of impact.

For the Raploch community, an aporia emerged in the fourth Learning Space: 
- Being proud and strong community with its own identity and narrative of its history; at the same time, participants described their need to portray the Raploch as in need and deserving: ‘We deserve regeneration'; 'We deserve free services/a project like Big Noise and a big new building'.

There were also some aporias in the relationship between Sistema Scotland and the Knowledge Exchange Team:

- Sistema Scotland's need for an impact study; and the Knowledge Exchange Team's need to report on process rather than outcome.

- Sistema Scotland's desire for the documentation of positive impact; alongside a discomfort with any feedback which is not positive.

- Sistema Scotland's desire for the expertise and skills of the researchers; but finding their ways of working (and possibly the researchers themselves) to be frustrating.

Through knowledge exchange meetings among SSKET and the Sistema Scotland project officers, alongside the Learning Spaces, SSKET and Sistema Scotland sought practical ways in which the exchange might bear fruit. We found that certain 'openings' came about through specific points of collaborative practical work. The decision to collect and articulate 'Frequently Asked Questions' arose with the aim of assisting Big Noise in their continuous and time-consuming interface with the public. This seemed to be a point in the project when we began to clarify aporias and the different contexts of knowledge: it focused everyone's mind on the variety of people involved in asking questions about Big Noise and the range of people who could 
provide answers. In sharing this work with the Sistema Scotland Director and Marketing Manager and making the process more collaborative, we created a focus for discussion that gave us some common ground and this helped address some of the aporias associated with the way that knowledge was being expressed through different professional contexts.

When the Sistema Scotland Director and Marketing Manager worked on responses to those 'Frequently Asked Questions'- which arose directly from the Learning Spaces and our knowledge exchange meetings - they described how valuable they had found the process of writing those responses: the process of reflection in that collaborative task forced some of the aporias to the surface and this was seen as a positive process and - crucially - a helpful one.

\section{The future of knowledge exchange}

The topic and participants in this particular knowledge exchange project were unusual but various outcomes could be relevant to other knowledge exchange contexts. The range of individuals and groups who may have an investment in any social-change project is obviously broad - the researchers, the project officers, the musicians, the children, other stakeholders, service providers and the wider Raploch community all played a part in the knowledge exchange processes around the establishment of Big Noise in the Raploch. Some groups and individuals have more power than others when it comes to decision-making. All groups are motivated by various factors that produce a great variety of contexts of knowledge about Big Noise. Given the variation 
in decision-making power, the contexts of knowledge for some groups have a greater impact than others.

Knowledge exchange opportunities may be more productive when the factors that give shape to these contexts of knowledge can be taken into account - but for some groups, these contexts of knowledge (and the encounter with the inherent aporias) are not well-formed. The meetings between the researchers and the project officers were most fruitful when a collaborative task provided a focus for critical reflection. This collaborative task - the discussion and development of Frequently Asked Questions regarding the Big Noise programme - was effective on two counts. Firstly, its content was derived from a very wide range of stakeholders, representing diverse contexts of knowledge. Secondly, the concrete act of collaborative working made a richer knowledge transaction possible. By providing a critical focus for communicative elaboration and exchange, aporias could be placed, productively, at the centre of the knowledge exchange process, allowing for the possibilities of opening up 'that-which cannot-be-thought’ (Critchley 1999, 29).

\section{References}

Abernathy, T., Coutts, J., Royce, D., Bartram, J., Kramer, D., Chapesike, K., Gold, I. \& March, I. 2001. Knowledge transfer: Looking beyond health. Report on the conference held in Toronto, 26-28 October, 2000.

Author, J. 2008. Rethinking inclusive education: The philosophers of difference in practice. Dordrecht: Springer. 
Author, J. 2009. (Eds) Social capital, professionalism and diversity. Rotterdam: Sense.

Ball, S. 2009. The governance turn! Editorial. Journal of Education Policy 24, no. 5, 537-538.

Booth, E. 2009. Thoughts on seeing El Sistema. Teaching Artist Journal 7, no. 2, 7584.

Chang, J. 2007. Orchestrating an 'affluence of spirit': Addressing self-esteem in impoverished Venezuelan Children through music education. Unpublished BA Honours Thesis. Harvard College.

Critchley, S. 1999. The ethics of deconstruction. Edinburgh: Edinburgh University Press.

Derrida, J. 1992. The other heading: Reflections on today’s Europe, Trans P. Brault \& M. Naas. Bloomington and Idianapolis: Indiana University Press.

Derrida, J. 1993. Aporias. Stanford: Stanford University Press.

Author (2009) Mapping the use of ICT in creative music practice. In Modern methods of musicology, ed. T. Crawford \& L. Gibson. Farnham: Ashgate.

Engeström, Y. (1987). Learning by expanding. Helsinki: Orienta-Konsultit Oy.

Egéa-Kuene, D. 2001. Derrida's ethics of affirmation: The challenge of educational rights and responsibility. In Derrida \& Education, ed. G. Biesta \& D. EgéaKuene. London: Routledge.

Author (2009) Finding out what we know. Sounding Board, Issue 4, 9-12.

Lieberman, T. 2009. Classical music as an agent for social change: Documenting an emerging movement. Unpublished report. University of North Carolina School of the Arts. 
Lingard, B. \& Ozga, J. 2007. Globalization, educational policy and politics. In The RoutledgeFalmer reader in educational policy and politics, ed. B. Lingard \& J. Ozga. London: Routledge.

McPherson, G. (Ed.). 2006. The child as musician: A handbook of musical development. Oxford, UK; New York: Oxford University Press.

Author, N. 2007. Measuring musical interaction: Analysing communication in embodied musical behaviour. Unpublished PhD, Open University, Milton Keynes.

Author, N. 2009. Symphony orchestras, sitars and Samba schools - How does community affect musical development? In Sound progress: Musical development, ed. H. Coll \& A. Lamont. National Association of Music Educators.

Ozga, J. 2009. Governing education through data in England: from regulation to selfevaluation. Journal of Education Policy, 24, no. 2: 149-162.

Ozga, J. \& Jones, R. 2006. Travelling and embedded policy: The case of knowledge transfer. Journal of Education Policy 21, no. 1: 1-17.

Pitts, S. E. 2005. Valuing musical participation. Aldershot: Ashgate.

Schellenberg, G. E. 2005. Music and cognitive abilities. Current Directions in Psychological Science 14, no. 6: 317-320.

Scottish Funding Council. no date. Knowledge exchange: How does SFC help Scotland's colleges and universities exchange knowledge? Retrieved on 9 June 2009, from: http://www.sfc.ac.uk/publications/sfc_leaflet_series/downloads/SFC_HelpKnowl edge.pdf 